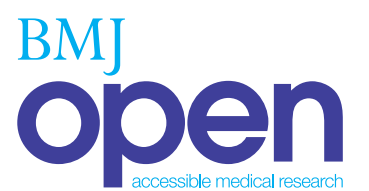

\title{
Early assisted discharge with generic community nursing for chronic obstructive pulmonary disease exacerbations: results of a randomised controlled trial
}

\author{
Cecile M A Utens, ${ }^{1,2}$ Lucas M A Goossens, ${ }^{3}$ Frank W J M Smeenk, ${ }^{1}$ \\ Maureen P M H Rutten-van Mölken, ${ }^{3}$ Monique van Vliet, ${ }^{4}$ Maria W Braken, ${ }^{5}$ \\ Loes M G A van Eijsden, ${ }^{6}$ Onno C P van Schayck ${ }^{2}$
}

To cite: Utens CMA,

Goossens LMA,

Smeenk FWJM, et al. Early

assisted discharge with

generic community nursing

for chronic obstructive

pulmonary disease

exacerbations: results of a

randomised controlled trial.

BMJ Open 2012;2:e001684.

doi:10.1136/bmjopen-2012-

001684

- Prepublication history and additional material for this paper are available online. To view these files please visit the journal online (http://dx.doi.org/10.1136/ bmjopen-2012-001684).

Received 18 June 2012 Accepted 4 September 2012

This final article is available for use under the terms of the Creative Commons Attribution Non-Commercial 2.0 Licence; see http://bmjopen.bmj.com

For numbered affiliations see end of article.

Correspondence to Cecile Utens; cecileutens@gmail.com

\section{ABSTRACT}

Objectives: To determine the effectiveness of early assisted discharge for chronic obstructive pulmonary disease (COPD) exacerbations, with home care provided by generic community nurses, compared with usual hospital care.

Design: Prospective, randomised controlled and multicentre trial with 3-month follow-up.

Setting: Five hospitals and three home care organisations in the Netherlands.

Participants: Patients admitted to the hospital with an exacerbation of COPD. Patients with no or limited improvement of respiratory symptoms and patients with severe unstable comorbidities, social problems or those unable to visit the toilet independently were excluded.

Intervention: Early discharge from hospital after 3 days inpatient treatment. Home visits by generic community nurses. Primary outcome measure was change in health status measured by the Clinical COPD Questionnaire (CCQ). Treatment failures, readmissions, mortality and change in generic health-related quality of life (HRQL) were secondary outcome measures.

Results: 139 patients were randomised. No difference between groups was found in change in CCQ score at day 7 (difference in mean change $0.29(95 \% \mathrm{Cl}-0.03$ to 0.61 )) or at 3 months (difference in mean change $0.04(95 \% \mathrm{Cl}-0.40$ to 0.49$))$. No difference was found in secondary outcomes. At day 7 there was a significant difference in change in generic HRQL, favouring usual hospital care.

Conclusions: While patients' disease-specific health status after 7-day treatment tended to be somewhat better in the usual hospital care group, the difference was small and not clinically relevant or statistically significant. After 3 months, the difference had disappeared. A significant difference in generic HRQL at the end of the treatment had disappeared after 3 months and there was no difference in treatment failures, readmissions or mortality. Early assisted discharge with community nursing is feasible and an alternative to usual hospital care for selected patients with an acute COPD exacerbation.

\section{ARTICLE SUMMARY}

Article focus

- What is the effectiveness of early assisted discharge with community nursing for chronic obstructive pulmonary disease (COPD) exacerbations in comparison with usual hospital care as measured by the Clinical COPD Questionnaire (CCQ).

Key messages

- There is no short-term or long-term difference in change in health status as measured by the CCD.

- A significant difference in generic health-related quality of life at the end of the treatment disappeared after 3 months.

- Early assisted discharge with home visits by community nurses is a feasible and an alternative to usual hospital care for selected patients with an acute exacerbation of their COPD.

Strength and limitations of this study

- One hundred and thirty-nine patients were randomised where 165 was calculated to be the required sample size. However, because the difference between the groups was only 0.29 instead of 0.4 it is unlikely that this difference would have increased to the clinically relevant difference of 0.4 with an additional 26 patients.

- This study is the first larger randomised controlled trial on early assisted discharge in the Dutch healthcare system.

Trial registration: NetherlandsTrialRegister NTR 1129.

\section{INTRODUCTION}

Chronic obstructive pulmonary disease (COPD) is a chronic disease with high prevalence, ${ }^{1}$ mortality and morbidity. ${ }^{2}{ }^{3}$ Exacerbations of 
the disease have negative effects on patient outcomes ${ }^{4-6}$ and are the main cause for hospitalisation. ${ }^{7}$ Hospitalisations are not only the main cost driver in COPD, they also put pressure on scarce hospital beds, especially during winters. ${ }^{8}$ Several studies have shown that some patients with an exacerbation, who would otherwise be admitted to the hospital, can be treated at home safely after examination in the emergency department or a short hospital admission. ${ }^{9-16}$ This is called hospital-at-home. Hospital-at-home aims to avoid admission, or reduce length of stay (early assisted discharge schemes). Previous studies found no differences in readmissions, mortality and disease-specific quality of life between hospital-at-home and usual hospital care. $^{9-11} 15 \quad 16$ Most published hospital-at-home studies originate from the UK and Spain, where this service is mainly provided by hospital-based respiratory nurses who visit patients at home. Davison et al ${ }^{17}$ and Nicholson et $a l^{18}$ suggested the use of non-specialised 'generic' community nursing teams for home supervision to increase the capacity of hospital-at-home schemes.

The Netherlands has a nation-wide, good infrastructure for community nursing, which could be used for hospital-at-home. Therefore we designed an early assisted discharge hospital-at-home scheme for COPD exacerbations, mainly operated by generic community nurses who performed the home visits. ${ }^{19}$ Main objective of the GO AHEAD study (GO AHEAD is the acronym for Assessment Of Going Home under Early Assisted Discharge) was to determine the effectiveness and cost-effectiveness of early assisted discharge followed by community-based nursing care at home. In addition, evaluation of patient satisfaction and preferences, carer strain and preferences and an evaluation among professional care providers were performed. The focus of this paper is on the effectiveness of early assisted discharge, with the Clinical COPD Questionnaire (CCQ) as the primary outcome measure. In addition, treatment failures, readmissions, mortality and generic quality of life were assessed as secondary outcomes.

\section{METHODS}

GO AHEAD was a randomised controlled trial comparing usual hospital care with early assisted discharge for COPD exacerbations. Five hospitals and three home care organisations participated. Treatment consisted of 7 days in-hospital care as usual or 3 days in-hospital treatment followed by 4 days care at home. Patients were followed until 3 months after randomisation.

All patients admitted to one of the participating hospitals with a COPD exacerbation, as diagnosed by the reviewing physician, were screened for potential eligibility on their first day of admission according to the inclusion and exclusion criteria (table 1). On day 3 of admission, clinical stability was assessed in patients who gave written informed consent (see randomisation criteria in table 1). For each hospital separately, participating patients were randomised on day 3 of admission, in a 1:1 ratio using a block-size of 6 . Randomisation was performed by the study nurses. The randomisation sequence was computer generated a priori by an independent researcher. Allocation sequence was placed in sealed envelopes. The study was approved by the Ethics

Table 1 Inclusion and exclusion criteria (applied at admission) and randomisation criteria (applied at day 3 of admission)

\section{Inclusion criteria (checked on day 1 )}

Age $\geq 40$ years

Competent to give informed consent

Diagnosed with COPD. COPD was defined as at least GOLD stage I and 10 pack years of smoking

Hospitalisation for COPD exacerbation

\section{Exclusion criteria (checked on day 1)}

Major uncontrolled co morbidity, including pneumonia that is prominent, heart failure that is prominent or acute changes on ECG and (suspected) underlying malignancy

Mental disability, including dementia, impaired level of consciousness and acute confusion

Living outside care region of the home care organisation

Inability to understand the programme

Indication for admission to intensive care unit or for non-invasive ventilation

Active alcohol and/or drug abuse

Insufficient availability of informal care at home

\section{Randomisation criteria (checked on day 3 )}

Completed Informed Consent on day three of admission

Acceptable general health:

- Decrease physical complaints

- Non-dependency of therapies that cannot be given at home (intravenous therapy and newly prescribed oxygen supply)

- Being able to visit toilet independently

Normal or moderately increased blood sugar levels, defined as $\leq 15$ or $\geq 15 \mathrm{mmol} / \mathrm{l}$ but patient is capable to regulate blood sugar levels independently

Respiratory complaints of dyspnoea, wheezing and rhonchi must have decreased in comparison with day of admission

COPD, chronic obstructive pulmonary disease. 
Committee of the Catharina Hospital, the Netherlands, approval number M07-1755.

During the first 3 days of the admission all patients were treated in the hospital according to the study protocol. ${ }^{19}$ Treatment consisted of systemic corticosteroids, nebulised bronchodilators and antibiotics and oxygen upon indication. Exacerbation symptoms were scored each day. Physiotherapists visited all patients for instruction of breathing and coughing techniques. On the fourth day of admission all randomised patients switched to oral medication and metered-dosed inhalations. Patients randomised to early assisted discharge were discharged home on the fourth day of admission and further treated at home. Community nurses visited or contacted the patient at least once daily on the day of discharge and the three consecutive days. They continued to score exacerbation symptoms and provided reassurance and counselling. Furthermore, medication compliance and inhalation techniques were addressed. Community nurses had the highest levels of generic nursing training in the Netherlands. No additional training was provided for the trial. The nurses could contact the hospital to discuss the patient's condition. If necessary, patients were readmitted to the hospital. For patients a $24 \mathrm{~h}$ telephone access to the hospital respiratory ward was installed for emergencies.

Patients in the usual hospital care group received care as usual at the discretion of the hospital staff. General practitioners were informed about the patient's participation in the trial and the discharge date. Clinical responsibility during home care remained with the respiratory physician. A detailed description of the research protocol and the early assisted discharge intervention has been published previously. ${ }^{19}$

Primary outcome was the change in CCQ scores between baseline ( $\mathrm{T} 0=$ day 3 of admission) and the end of the supervised treatment ( $\mathrm{T}+4$ days). The CCQ is a disease-specific questionnaire measuring health status. ${ }^{20} \mathrm{It}$ consists of 10 questions in three domains: symptoms, functional state and mental state, resulting in an overall, continuous score varying from 6 (worst score) to 0 (best score) ${ }^{20}$ In order to produce a valid overall score, three, three and two questions on the symptoms domain, functional state and mental state domain, respectively, need to be answered. The CCQ has proved to be responsive to change. The minimal clinical important difference is $0.4{ }^{21}$ Secondary outcomes were: (1) change in CCQ scores between baseline and 3 months after randomisation ( $\mathrm{T}+90$ days); (2) number of treatment failures (ie, either death or clinical deterioration leading to prolonged hospital stay beyond the standardised 7 days (usual hospital care) or death or readmission during the 4 days treatment at home (early discharge)); (3) mortality; (4) readmissions during the 3 month follow-up and (5) generic healthrelated quality of life measured by the EuroQol-5D $(\mathrm{EQ}-5 \mathrm{D})^{22}$ at baseline, $\mathrm{T}+4$ days and $\mathrm{T}+90$ days. Utilities were calculated using the Dutch value set. ${ }^{22}$ Higher scores represent better generic quality of life.

\section{Statistical analysis}

To detect a difference of 0.4 in $\mathrm{CCQ}$ change scores between the two groups, in favour of the early discharge group, with a power of 0.80 and $\alpha$ of 0.05 , with SD in the usual hospital care group of 0.922 and 0.988 in the early discharge group, the required sample size was $165 .{ }^{19}$ Change in CCQ scores and EQ-5D scores was analysed using a linear repeated measures model with correlated errors. An unstructured covariance matrix for the residuals of the different measurements was used. Backward selection of covariates was applied. In addition to time (ie, measurement at $\mathrm{T}+4$ days, end of treatment and $\mathrm{T}+90$ days, end of follow-up), the interaction of time and treatment, the following variables were tested: baseline CCQ or EQ-5D score, treatment centre, age, gender, comorbidity, ${ }^{23}$ smoking status, living situation, availability informal caregiver, presence of home care prior to admission, course of oral corticosteroids and/or antibiotics prior to admission. Variables were retained in the model if their exclusion led to a $10 \%$ change in the estimated treatment effect. ${ }^{24}$ For the analysis of CCQ scores, only baseline score was included in the final model. For the analysis of EQ-5D scores, baseline score, comorbidity and gender were included. Results are presented as mean differences in change and 95\% CI. Numbers of patients with treatment failures, readmissions and mortality were analysed using multiple logistic regression analysis. Numbers of readmissions per patient in each group were analysed in a Poisson regression. Time to readmission was analysed with a Cox proportional hazards model. Results are presented as OR or HR with 95\% CI. Again, backward selection was used to select covariates. Only baseline CCQ score was retained in the models. The significance level for a difference between treatment groups was set at $\mathrm{p} \leq 0.05$. All analyses were performed using the Statistical Package for Social Sciences (SPSS), V.17.0, IBM.

\section{RESULTS}

In total, 1371 patients were screened for eligibility between November 2007 and March 2011, of whom 508 met the criteria for eligibility on day 1 . Figure 1 shows an overview of the patient flow during the trial from hospital admission to the end of the follow-up. Three patients in the early assisted discharge group and seven in the usual hospital care group were not satisfied with the allocated place of treatment and withdrew consent immediately after randomisation. The total dropout over the study period was $16 \%, 25 \%$ in the usual hospital care group and $10 \%$ in the early assisted discharge group. Baseline CCQ scores of patients dropping out were not different from those who completed the study, but they did have more comorbidities. At T+4 days 118 of 129 still participating patients produced a valid overall score on the CCQ and were included in the analysis. The other patients did not withdraw consent and continued to participate in the study in order to contribute to 


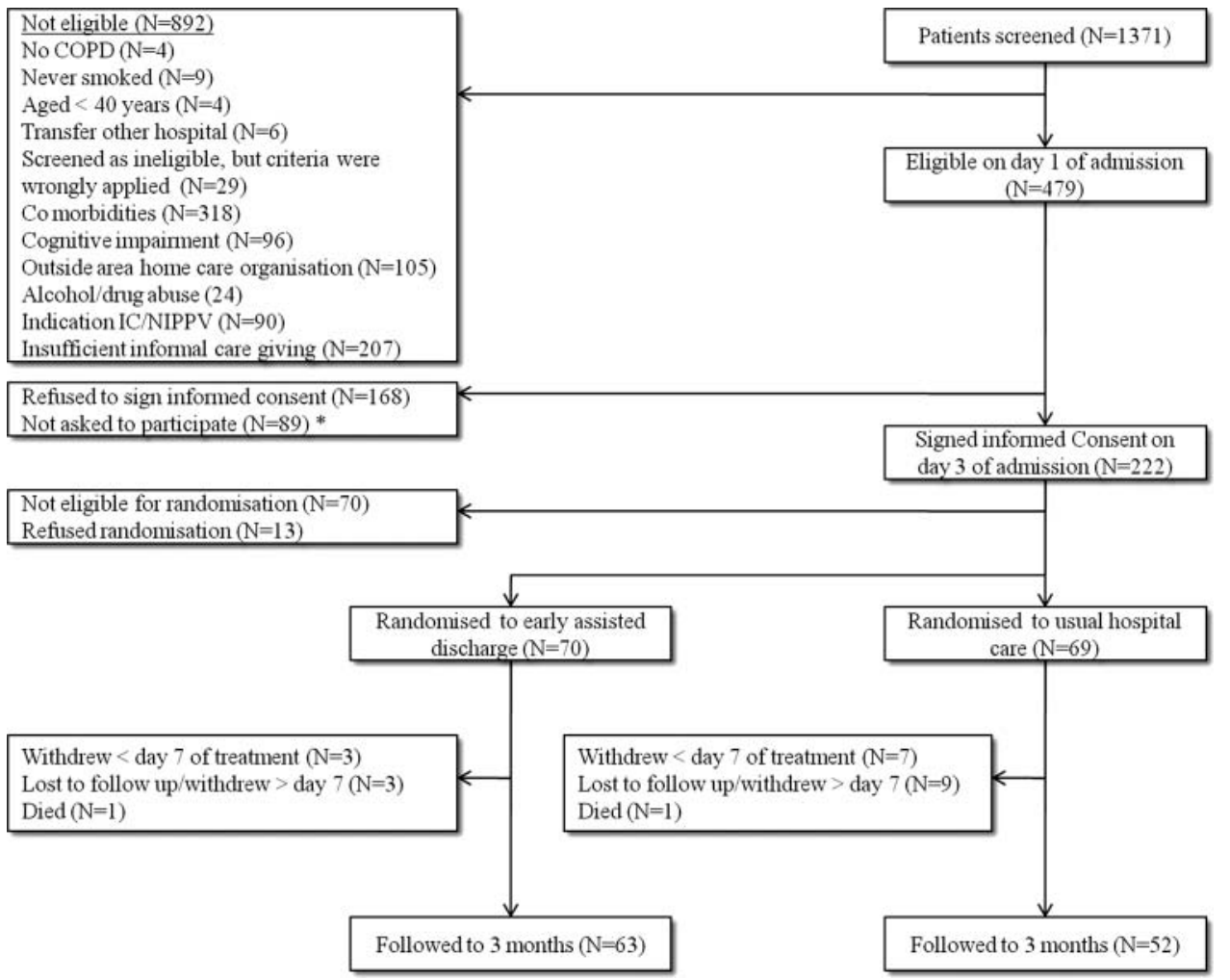

Figure 1 Patient flow through study.

*Not asked to participate because of logistical reasons (eg no study staff available or patient not admitted to respiratory ward).

the other analyses and to produce a valid score at other measuring points. This approach fits with the intentionto-treat principle and the repeated measures analysis. At $\mathrm{T}+90$ days, 101 of 115 patients produced a valid overall CCQ score.

Table 2 shows the baseline characteristics of randomised patients by treatment group. These were comparable across the groups. At the end of follow-up period lung function testing was performed by which classification of disease severity according to the GOLD criteria $^{2}$ could be made (see table 3 ).

Table 4 shows the unadjusted CCQ scores at the different measuring points. At T0 CCQ scores were 2.22 (0.97) for the usual hospital care group and 2.63 (1.06) for the early discharge group. Figure 2 shows the change in CCQ scores from T0, adjusted for baseline score. CCQ scores improved between $\mathrm{T} 0$ and $\mathrm{T}+4$ days for the usual hospital care group, and were almost stable for the early assisted discharge group, but there was no significant difference between the groups at $\mathrm{T}+4$ days (difference in mean change from T0 0.29, 95\% CI -0.03 to $0.61, \mathrm{p}=0.078)$. At $\mathrm{T}+90$ days, CCQ scores of both groups were slightly higher in comparison with T0. There was no difference between the groups at 3 months (difference in mean change from T0 0.04 , $95 \%$ CI -0.40 to $0.49, \mathrm{p}=0.858)$.

Treatment failed in five patients. One patient in the early discharge group needed readmission to the hospital because of deterioration of respiratory symptoms, before the end of the home treatment and four patients in the usual hospital care group required hospital admission beyond the 7 days that were stated in the protocol (two because of deterioration of respiratory symptoms, two patients because of deterioration of general condition due to gastroenteritis caused by norovirus). This difference was not significant (OR early discharge group 0.27, 95\% CI 0.026 to $2.70, \mathrm{p}=0.263$ ). Table 5 shows the number of readmissions during follow-up. Seventeen patients in each group had one or more readmission to the hospital of which 14 first readmissions were due to an exacerbation or other pulmonary indication (OR early discharge group $0.80,95 \%$ CI 0.36 to $1.79, \mathrm{p}=0.592)$. There was no difference in the number of readmissions per patient between the groups, or in the total number of readmissions in each group. There was no difference in time to first readmission between the two groups (HR early discharge group 0.77 , $95 \%$ CI 0.39 to $1.53, \mathrm{p}=0.461)$.

No patient died during the hospital or home treatment, but one patient from each group died during follow-up. Cause of death was unknown in one case (patient died during sleep at home) and an acute abdomen in the other. Both were not related to the trial.

EQ-5D utility scores (SD) at T0 were $0.713(0.22)$ for the usual hospital care group and 0.664 (0.26) for the early assisted discharge group. Table 6 shows the mean changes and mean difference in change from baseline of EQ-5D utility. In the usual hospital care group, mean utility scores improved from $\mathrm{T} 0$ to $\mathrm{T}+4$ days and decreased to baseline at $\mathrm{T}+90$ days. In the early assisted discharge group mean utility scores remained close to 
Table 2 Baseline characteristics and treatment at admission

\begin{tabular}{|c|c|c|}
\hline Characteristic & $\begin{array}{l}\text { Usual hospital care } \\
(\mathrm{N}=69)\end{array}$ & $\begin{array}{l}\text { Early assisted discharge } \\
(\mathrm{N}=70)\end{array}$ \\
\hline Age (years) & $67.8(11.3)$ & $68.3(10.3)$ \\
\hline Men $n(\%)$ & $38(55.1)$ & $48(68.6)$ \\
\hline \multicolumn{3}{|l|}{ Smoking history } \\
\hline Current smokers n (\%) & $27(39.1)$ & $23(32.9)$ \\
\hline \multirow[t]{2}{*}{ Pack years, median interquartile range } & 37 & 44 \\
\hline & 36.9 & 26.7 \\
\hline Body mass index $\left(\mathrm{kg} / \mathrm{m}^{2}\right)$ & $25.6(4.3)$ & $25.0(5.1)$ \\
\hline Charlson comorbidity score ${ }^{\star 23}$ & $1.68(1.1)$ & $1.74(1.1)$ \\
\hline Comorbidity score of $1 \mathrm{n}(\%)$ & $42(60.0)$ & $38(54.0)$ \\
\hline Comorbidity score >1 n (\%) & $27(39.0)$ & $32(46.0)$ \\
\hline \multicolumn{3}{|l|}{ Living situation } \\
\hline Living alone $\mathrm{n}(\%)$ & $21(30.4)$ & $22(31.4)$ \\
\hline Receiving care at home before admission $n(\%)$ & $16(23.2)$ & $17(24.3)$ \\
\hline \multicolumn{3}{|l|}{ Treatment at admission } \\
\hline Long-term oxygen treatment $\mathrm{n}(\%)$ & $4(5.8)$ & $5(7.1)$ \\
\hline Oral steroids $\mathrm{n}(\%)$ & $5(7.2)$ & $10(14.3)$ \\
\hline Course of oral steroids prior to admission $\mathrm{n}(\%)$ & $34(50.0)$ & $35(50.7)$ \\
\hline Course antibiotics prior to admission $\mathrm{n}(\%)$ & $31(45.6)$ & $32(46.4)$ \\
\hline Inhaled $\beta 2$-agonist (LABA) n (\%) & $9(13.0)$ & $7(10.0)$ \\
\hline Inhaled corticosteroid n (\%) & $3(12.0)$ & $3(15.0)$ \\
\hline Inhaled corticosteroid/LABA combination n (\%) & $44(63.7)$ & $50(71.4)$ \\
\hline \multicolumn{3}{|l|}{ Inhaled anticholinergic n (\%) } \\
\hline Tiotropium & $31(44.9)$ & $36(51.4)$ \\
\hline Ipratropium & $12(17.4)$ & $13(18.6)$ \\
\hline $\begin{array}{l}\text { Followed rehabilitation programme in year prior to admission } n \\
(\%)\end{array}$ & $10(14.9)$ & $12(17.4)$ \\
\hline Heart Rate (beats/min) & $91.0(14.2)$ & $95.6(18.4)$ \\
\hline Arterial blood gas $†$ & $\mathrm{~N}=37$ & $\mathrm{~N}=42$ \\
\hline $\mathrm{pH}$ & $7.44(0.05)$ & $7.43(0.04)$ \\
\hline $\mathrm{pO}_{2}(\mathrm{~mm} \mathrm{Hg})$ & 70.7 (13.2) & $67.3(8.1)$ \\
\hline $\mathrm{pCO}_{2}(\mathrm{~mm} \mathrm{Hg})$ & $37.2(6.2)$ & 39.1 (5.3) \\
\hline Saturation & $94(2.5)$ & $94(3.6)$ \\
\hline
\end{tabular}

Values represent mean (SD), unless stated otherwise.

${ }^{*}$ Charlson comorbidity index, $1=$ only COPD, higher score means more comorbidities.

†Only data of blood gas measurements in patients without oxygen supplement.

COPD, chronic obstructive pulmonary disease; LABA, long-acting $\beta 2$ agonist.

baseline. The mean change in utility scores on $\mathrm{T}+4$ days was significant greater in the usual hospital care group. At $\mathrm{T}+90$ days this difference between treatment groups had disappeared.

\section{DISCUSSION}

This is the first randomised controlled trial that investigated the effectiveness of early assisted discharge for COPD exacerbations with supervision at home by community nurses. In addition, this is the first evaluation of early discharge for this disease in the Dutch healthcare system. While patients' disease-specific health status as expressed in the mean CCQ score after7 days treatment tended to be somewhat better in the usual hospital care group, the difference was small, not clinically relevant and not statistically significant. After 3 months, the difference had disappeared. The same pattern was found in generic health-related quality of life measured with the EQ-5D, although this difference was statistically significant at the end of the supervised treatment. The difference had disappeared at the end of the 3-month follow-up period. There was no difference in treatment failures, readmissions or mortality.

Table 3 Lung function testing at the end of 3-month follow-up

\begin{tabular}{lll}
\hline & $\begin{array}{l}\text { Usual } \\
\text { hospital care }\end{array}$ & $\begin{array}{l}\text { Early assisted } \\
\text { discharge }\end{array}$ \\
\hline $\begin{array}{l}\text { Postbronchodilator FEV } 1 \\
\text { (litres) }\end{array}$ & $1.25(0.07)$ & $1.21(0.07)$ \\
$\begin{array}{l}\text { Percentage of predicted } \\
\text { postbronchodilator FEV }\end{array}$ & $50.29(2.71)$ & $45.20(2.13)$ \\
GOLD stage I, n (\%) & $7(10.3)$ & $2(2.9)$ \\
GOLD stage II, n (\%) & $22(32.4)$ & $23(32.9)$ \\
GOLD stage III, n (\%) & $28(41.2)$ & $31(44.3)$ \\
GOLD stage IV, n (\%) & $11(16.2)$ & $14(20.0)$ \\
\hline
\end{tabular}

Values represent mean (SD), unless stated otherwise. 
Table 4 Unadjusted mean (SD) CCQ total scores at each time of measurement by treatment group

\begin{tabular}{lll}
\hline $\begin{array}{l}\text { Time of } \\
\text { measurement }\end{array}$ & $\begin{array}{l}\text { Usual hospital } \\
\text { care }\end{array}$ & $\begin{array}{l}\text { Early assisted } \\
\text { discharge }\end{array}$ \\
\hline T-2 days & $3.21(1.07)$ & $3.49(1.07)$ \\
T0 & $2.22(0.97)$ & $2.63(1.06)$ \\
T+4 days & $2.00(1.09)$ & $2.55(1.21)$ \\
T+90 days & $2.41(1.14)$ & $2.70(1.32)$ \\
\hline CCQ total score range is $0-6 ; 0$ represents best possible score \\
and 6 represents worst possible score. \\
CCQ, clinical chronic obstructive pulmonary disease \\
queationnaire.
\end{tabular}

These study results confirm previously published positive results by Davison et $a l^{17}$ and Nicholson et $a l^{18}$ but these two studies were either not randomised ${ }^{17}$ or included a small number of patients. ${ }^{18}$ We found no significant difference in CCQ scores, which corresponds with the findings of Davies et $a l^{9}$ and Hernandez et $a l^{16}$ who found no differences in disease-specific quality of life measured with the St George's Respiratory Questionnaire. Furthermore, our results are in line with those of earlier studies involving specialised hospitalbased nurses. $^{9-12} 15162526$ The readmission rate in our study was $25 \%$, which is comparable to the $30 \%$ in previously published studies. $^{9-11}$ Characteristics like age, smoking history and living situation of patients in our study were similar to those in studies from the UK ${ }^{9-12}$ and to that of a survey on hospital-at-home services in British hospitals by Quantrill et al. ${ }^{27}$

Earlier studies did not measure the impact of hospital-at-home on generic health-related quality of life.

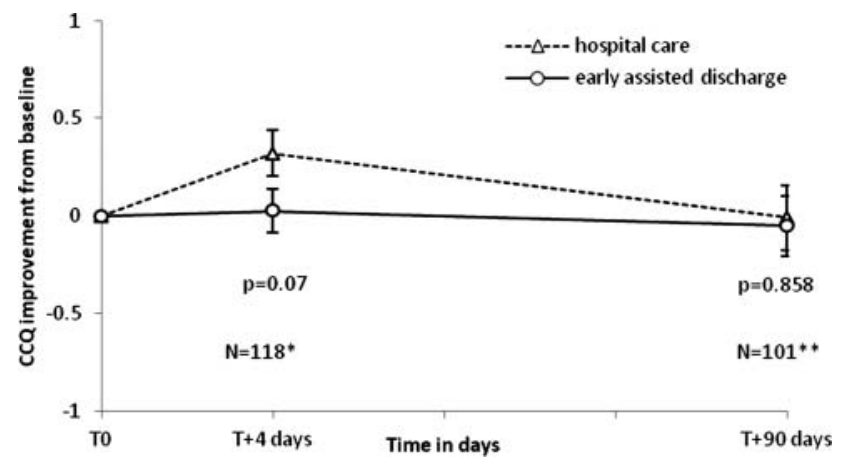

Figure 2 Clinical chronic obstructive pulmonary disease questionnaire total score, differences in mean change from baseline. Error bars represent standard errors. $p$ Values are based on repeated measures analysis, adjusted for baseline value.

*Number of patients at T+4 days who completed questionnaire that produced a valid total score; ${ }^{* *}$ Number of patients at $T+90$ days who completed questionnaire that produced a valid score.

Note: for interpretation reasons the sign of the CCQ has been reversed. Positive change in $C C Q$ scores represents improvement in the patient's condition, which is a decrease in CCQ score.

\begin{tabular}{|c|c|c|}
\hline & $\begin{array}{l}\text { Usual } \\
\text { hospital } \\
\text { care }\end{array}$ & $\begin{array}{l}\text { Early assisted } \\
\text { discharge }\end{array}$ \\
\hline Patients with readmission & $17(25)$ & $17(24)$ \\
\hline \multicolumn{3}{|c|}{ Patients with one, two or $\geq$ three readmissions } \\
\hline One readmission & 11 & 12 \\
\hline Two readmissions & 4 & 3 \\
\hline $\begin{array}{l}\text { Three or more } \\
\text { readmissions }\end{array}$ & 2 & 2 \\
\hline $\begin{array}{l}\text { Average }(S D) \text { time to first } \\
\text { readmission in days }\end{array}$ & $61(36.5)$ & $69(33.8)$ \\
\hline
\end{tabular}

We found a significant difference between the two groups, in favour of usual hospital care, at the end of the hospital and home treatment. This difference had disappeared after 3 months. The utility scores are in line with O'Reilly et $a l^{28}$ but they found much worse scores at admission than in our study, probably because we did not include patients with more severe exacerbations. Utility and CCQ scores in both groups follow the same pattern. The greater improvement in CCQ and EQ-5D scores of the usual hospital care group at the end of the hospital treatment in comparison with the early discharge group may reflect a true difference in recovery, in which case usual hospital care is the preferred treatment. However, an alternative explanation could be that patients who were discharged early were confronted with their symptoms and limitations earlier and more intensely when they tried to pick up normal life at home. Furthermore, some patients have difficulties viewing hospital care followed by early discharge as one treatment period. ${ }^{29}$ Expecting to be in a certain state at discharge, and experiencing this is not the case, might be expressed in worse scores on the CCQ and the EQ-5D.

In our trial multiple hospitals participated with different socioeconomic and geographic characteristics, which make it likely that our sample is representative of eligible patients. The percentage of admissions initially considered to be eligible for early discharge at admission was similar to that of previous studies $( \pm 37 \%)$. Early discharge is possible when the exacerbation is the main problem and comorbidities are (relatively) stable. The percentage of patients living alone suggests that this is not an absolute reason for exclusion, provided that patients have a sufficiently functioning social support system. Still, 25\% of screened patients were considered ineligible, because of living in a nursing home, overburden of informal caregiver(s) or living alone with insufficient social support. This suggests that social environment is an important factor when deciding for admission and (early) discharge. Finally, 37\% of screened patients were ineligible because of comorbidities.

Considering the very low number of treatment failures in the early discharge group it might be possible to relax the inclusion criteria and randomisation criteria. In our 
Table 6 Mean changes and mean differences in change for EQ-5D

\begin{tabular}{|c|c|c|c|c|c|}
\hline \multirow[b]{2}{*}{ Utility } & & \multicolumn{2}{|c|}{ Mean change from baseline (SE) } & \multirow{2}{*}{$\begin{array}{l}\text { Adjusted mean }(95 \% \mathrm{Cl}) \text { difference } \\
\text { in change from baseline* } \\
\text { Usual care-early discharge } \\
0.0746(0.010 \text { to } 0.139) \\
-0.022(-0.116 \text { to } 0.072)\end{array}$} & \multirow{2}{*}{$\begin{array}{l}\mathbf{p} \\
\text { Value } \\
0.024 \\
0.639\end{array}$} \\
\hline & $\begin{array}{l}T+4 \text { days } \uparrow \\
T+90 \text { days } \ddagger\end{array}$ & $\begin{array}{c}\text { Usual hospital care } \\
0.051(0.0261) \\
-0.036(0.0447)\end{array}$ & $\begin{array}{l}\text { Early assisted discharge } \\
-0.005(0.029) \\
0.008(0.039)\end{array}$ & & \\
\hline
\end{tabular}

trial, criteria were applied very strictly for safety reasons, but more patients with comorbidities might be eligible in daily practice. Furthermore, the strict review and exclusion of patients at day 1 of admission (eg, those treated with NIV), precluded patients from early discharge even if they had become eligible at day 3 of admission. Therefore, review of eligibility for early discharge should be performed after a few days of hospital treatment. Thirty per cent of patients who consented to participate were not randomised because they showed insufficient recovery and/or were depending on oxygen supply. Unlike in the British hospital-at-home schemes, patients were not sent home with nebulisers or oxygen cylinders, unless these were already part of their treatment. Extension of the treatment possibilities at home may enable early discharge of patient with more severe disease. However, it would also require more expertise of the nursing staff supervising patients at home, which might currently not be present in community-based home care organisations. Future research should focus on determining which treatments can be safely provided at home, which treatments require the supervision of generic or specialised nurses and which criteria should be applied for selecting eligible patients. In addition, a direct comparison between early discharge with generic and early discharge with specialised nursing care would provide more information on which scheme is most safe and effective.

Our study has some limitations. First, in total 139 patients were randomised, where a number of 165 was calculated to be needed to detect a difference of 0.4 in CCQ change scores between the two groups. A post hoc power analysis with these 139 patients and the actual variances in CCQ scores showed that the power to detect a difference in change from baseline of 0.4 between the groups was $73 \%$ instead of $80 \%$, which was aimed for. We believe that this slight reduction in power does not have a substantial influence on our final results, because the difference between the groups was only 0.29. It is highly unlikely that this difference would have increased to the clinically relevant difference of 0.4 with an additional 26 patients. In previous randomised studies of early discharge in patients diagnosed with COPD numbers varied between 25 and 222, and only 15-35\% of admitted patients was randomised. ${ }^{9-12} 1630$ Second, our study was not an equivalence trial, which would determine best whether hospital care and early discharge care are equally effective. However, in order to demonstrate equal effectiveness with CCQ score, over 500 patients would have been needed, which is beyond what is attainable in this population. Third, $16 \%$ of patients dropped out after randomisation. However, comparison of patients who dropped out with patients who completed the study only revealed more comorbidities for those who dropped out. CCQ scores were not different. Fourth, although our variable selection for the analyses is justifiable, treatment centre could also be considered as an important covariate in the analyses, based on the randomisation design of the study. However, adding treatment centre as additional fixed factor to the analyses did not result in different outcomes in any of the analyses. It was therefore omitted and the analyses remained unchanged. Finally, due to the nature of the intervention, patients and healthcare staff could not be blinded to the allocated group.

In conclusion, we found no significant short-term or long-term differences in outcomes between early discharge and usual hospital care, except for generic health-related quality of life at the end of treatment ( $\mathrm{T}+4$ days). Early assisted discharge with home visits by community nurses can reduce length of hospital stay for a selected group of patients admitted with a COPD exacerbation and is an alternative to usual hospital care. The decision to implement early assisted discharge with community nursing does not only depend on the results of the effectiveness analysis. Costs and cost-effectiveness evaluations are of high importance as well. An economic evaluation is currently being performed and results will be published separately.

\section{Author affiliations}

${ }^{1}$ Department of Respiratory Medicine, Catharina-hospital Eindhoven, Eindhoven, The Netherlands

${ }^{2}$ Department of General Practice, CAPHRI School for Public Health and Primary Care, Maastricht University, Maastricht, The Netherlands

${ }^{3}$ Institute for Medical Health Technology Assessment, Erasmus University, Rotterdam, The Netherlands

${ }^{4}$ Department of Respiratory Medicine, Atrium Medical Centre, Heerlen, The Netherlands

${ }^{5}$ Department of Staff nurses Nursing and Care, ZuidZorg, Veldhoven,

The Netherlands

${ }^{6}$ Department of Health Care Policy, Meander Group Zuid-Limburg, Heerlen, The Netherlands

Acknowledgements The authors thank all care professionals from the participating hospitals and home care organisations that made the trial and early assisted discharge possible: W van Litsenburg (Catharina-hospital), A Janssen (Catharina-hospital), W Seezink (Atrium Medical Centre), B van de Pas (Máxima Medical Centre), A van der Pouw (Rijnstate Hospital) and P de Laat (TweeSteden 
Hospital) who performed patient recruitment; R Eijsermans who coordinated the home care visits in the Tilburg region; D DeMunck (Máxima Medical Centre), J Retera (TweeSteden Hospital) and P de Bruijn (Rijnstate Hospital) who were responsible pulmonologists in the participating hospitals. We thank $\mathrm{K}$ van der Meer, research assistant, for her assistance in the data input.

Contributors CMAU was involved in patient recruitment, database management, administration of questionnaires, data analysis, data interpretation and wrote the manuscript. LMAG was involved in data analysis and data interpretation and preparation of the manuscript. FWJMS was local coordinating physician and involved in data interpretation and preparation of the manuscript. MPMHRvM designed the study and involved in data interpretation and preparation of the manuscript. MvV was local coordinating physician in the Atrium Medical Centre and involved in the preparation of the manuscript. MWB and LMGAvE were coordinators of the home care organisations and involved in the preparation of the manuscript. OCPvS designed the study and was involved in data interpretation and writing the manuscript. OCPVS is guarantor for the study. All researchers had access to all data.

Funding The study was funded by the Netherlands Organisation for Health Research and Development (ZonMw), grant application number 945-50-7730. The funder had no role in the design of the study; the collection analysis and interpretation of the data; or the writing of the article and the decision to submit the article for publication. All researchers were independent from the funder.

Competing interests 'All authors have completed the Unified Competing Interest form at www.icmje.org/coi_disclosure.pdf (available on request from the corresponding author) and declare that (1) LMAG, MPMHRvM, OCPvS have had support from ZonMw for the submitted work; (2) CMAU, FWJMS, MvV, MWB, LMGAvE have no relationships with companies that might have an interest in the submitted work in the previous 3 years; LMAG and MPMHRvM haves relationships (received grants to perform cost-effectiveness studies) from multiple pharmaceutical companies, OCPVS has relationships (consultancy) with Pfizer, Boehringer Ingelheim and Astra Zeneca that might have an interest in the submitted work in the previous 3 years; (3) their spouses, partners, or children have (specified) financial relationships that may be relevant to the submitted work and (4) CMAU, LMAG, FWJMS, MPMHRvM, MvV, MWB, LMGAvE and OCPvS have no non-financial interests that may be relevant to the submitted work.

Patient consent Obtained

Provenance and peer review Not commissioned; externally peer reviewed.

Data sharing statement No additional data are available.

\section{REFERENCES}

1. Buist AS, McBurnie MA, Vollmer WM, et al. International variation in the prevalence of COPD (the BOLD Study): a population-based prevalence study. Lancet 2007;370:741-50.

2. Rabe KF, Hurd S, Anzueto A, et al. Global strategy for the diagnosis, management, and prevention of chronic obstructive pulmonary disease: GOLD executive summary. Am J Respir Crit Care Med 2007; $176: 532-55$

3. Lopez AD, Shibuya K, Rao C, et al. Chronic obstructive pulmonary disease: current burden and future projections. Eur Respir $J$ 2006;27:397-412.

4. Seemungal TA, Donaldson GC, Paul EA, et al. Effect of exacerbation on quality of life in patients with chronic obstructive pulmonary disease. Am J Respir Crit Care Med 1998;157:1418-22.

5. Donaldson GC, Seemungal TA, Bhowmik A, et al. Relationship between exacerbation frequency and lung function decline in chronic obstructive pulmonary disease. Thorax 2002;57:847-52.

6. Esteban C, Quintana JM, Moraza J, et al. Impact of hospitalisations for exacerbations of COPD on health-related quality of life. Respir Med 2009;103:1201-8.

7. Toy EL, Gallagher KF, Stanley EL, et al. The economic impact of exacerbations of chronic obstructive pulmonary disease and exacerbation definition: a review. COPD 2010;7:214-28.
8. Jordan RE, Hawker JI, Ayres JG, et al. Effect of social factors on winter hospital admission for respiratory disease: a case-control study of older people in the UK. Br J Gen Pract 2008;58:400-2.

9. Davies L, Wilkinson M, Bonner S, et al. 'Hospital at home' versus hospital care in patients with exacerbations of chronic obstructive pulmonary disease: prospective randomised controlled trial. BMJ 2000;321:1265-8

10. Cotton MM, Bucknall CE, Dagg KD, et al. Early discharge for patients with exacerbations of chronic obstructive pulmonary disease: a randomized controlled trial. Thorax 2000;55:902-6.

11. Skwarska E, Cohen G, Skwarski KM, et al. Randomized controlled trial of supported discharge in patients with exacerbations of chronic obstructive pulmonary disease. Thorax 2000:55:907-12.

12. Ojoo JC, Moon T, McGlone S, et al. Patients' and carers' preferences in two models of care for acute exacerbations of COPD: results of a randomised controlled trial. Thorax 2002:57:167-9.

13. British Thoracic Society. Intermediate care-hospital-at-home in chronic obstructive pulmonary disease: British Thoracic Society guideline. Thorax 2007;62:200-10.

14. Diaz LS, Gonzalez LF, Gomez Mendieta MA, et al. Evaluation of a home hospitalization program in patients with exacerbations of chronic obstructive pulmonary disease. Arch Bronconeumol 2005;41:5-10

15. Gravil JH, Al-Rawas OA, Cotton MM, et al. Home treatment of exacerbations of chronic obstructive pulmonary disease by an acute respiratory assessment service. Lancet 1998;351:1853-5.

16. Hernandez C, Casas A, Escarrabill J, et al. Home hospitalisation of exacerbated chronic obstructive pulmonary disease patients. Eur Respir J 2003;21:58-67.

17. Davison AG, Monaghan M, Brown D, et al. Hospital at home for chronic obstructive pulmonary disease: an integrated hospital and community based generic intermediate care service for prevention and early discharge. Chron Respir Dis 2006;3:181-5.

18. Nicholson C, Bowler S, Jackson C, et al. Cost comparison of hospital- and home-based treatment models for acute chronic obstructive pulmonary disease. Aust Health Rev 2001;24:181-7.

19. Utens CM, Goossens LM, Smeenk FW, et al. Effectiveness and cost-effectiveness of early assisted discharge for chronic obstructive pulmonary disease exacerbations: the design of a randomised controlled trial. BMC Public Health 2010;10:618.

20. van der Molen T, Willemse BW, Schokker S, et al. Development, validity and responsiveness of the Clinical COPD Questionnaire. Health Qual Life Outcomes 2003:1:13.

21. Kocks JW, Tuinenga MG, Uil SM, et al. Health status measurement in COPD: the minimal clinically important difference of the clinical COPD questionnaire. Respir Res 2006;7:62.

22. Lamers LM, McDonnell J, Stalmeier PF, et al. The Dutch tariff: results and arguments for an effective design for national EQ-5D valuation studies. Health Econ 2006;15:1121-32.

23. Charlson ME, Pompei P, Ales KL, et al. A new method of classifying prognostic comorbidity in longitudinal studies: development and validation. J Chronic Dis 1987;40:373-83.

24. Rothman KJ, Greenland S, Lash TL. Modern epidemiology. 3rd edn Philidelphia: Lippincott Williams \& Wilkins, 2008.

25. Ansari K, Shamssain M, Farrow M, et al. Hospital-at-home care for exacerbations of chronic obstructive pulmonary disease: an observational cohort study of patients managed in hospital or by nurse practitioners in the community. Chron Respir Dis 2009;6:69-74.

26. Sala E, Alegre L, Carrera M, et al. Supported discharge shortens hospital stay in patients hospitalized because of an exacerbation of COPD. Eur Respir J 2001:17:1138-42.

27. Quantrill SJ, Lowe D, Hosker HS, et al. Survey of early discharge schemes from the 2003 UK National COPD Audit. Respir Med 2007;101:1026-31.

28. O'Reilly JF, Williams AE, Rice L. Health status impairment and costs associated with COPD exacerbation managed in hospital. Int $J$ Clin Pract 2007;61:1112-20.

29. Clarke A, Sohanpal R, Wilson G, et al. Patients' perceptions of early supported discharge for chronic obstructive pulmonary disease: a qualitative study. Qual Saf Health Care 2010;19:95-8.

30. Aimonino RN, Tibaldi V, Leff B, et al. Substitutive 'hospital at home' versus inpatient care for elderly patients with exacerbations of chronic obstructive pulmonary disease: a prospective randomized, controlled trial. J Am Geriatr Soc 2008:56:493-500. 